\title{
Role of India in Rohingya Crisis: Humanitarian Role and Geopolitical Interest
}

\author{
Farzana Al Ferdous
}

Assistant Professor, College of Tourism and Hospitality Management, IUBAT - International University of Business Agriculture and Technology, Dhaka, BANGLADESH

(faferdous@iubat.edu)

This journal is licensed under a Creative Commons Attribution-Noncommercial 4.0 International License (CC-BY-NC).

Articles can be read and shared for noncommercial purposes under the following conditions:

- BY: Attribution must be given to the original source (Attribution)

- NC: Works may not be used for commercial purposes (Noncommercial)

This license lets others remix, tweak, and build upon your work non-commercially, and although their new works must also acknowledge you and be non-commercial, they don't have to license their derivative works on the same terms.

License Deed Link: http://creativecommons.org/licenses/by-nc/4.0/

Legal Code Link: http://creativecommons.org/licenses/by-nc/4.0/legalcode

$A B C$ Research Alert uses the CC BY-NC to protect the author's work from misuse.

\section{Abstract}

Globally considered one of the most persecuted minority groups, the Rohingyas are a predominantly Muslim ethnic group in northern Rakhine who have fled Myanmar in a large-scale exodus since August 2017. More than 700,000 refugees fled to Bangladesh after a military crackdown on Rohingyas last August, following the Arakan Rohingya Salvation Army's attack on Myanmar's military posts. This massive refugee outflow of Rohingya Muslims from Myanmar into Bangladesh has created a humanitarian crisis that carries implications on regional stability and security and also outrage among the international community. As a neighbor country, Bangladesh expects India's respond promptly to support the government. This paper briefly examines India's approach towards the Rohingya crisis and explores ways for India through its role in humanitarian and geopolitical including diplomatic, domestic political compulsions, security and economic interest. It also analyses India's response to the Rohingya crisis focusing on India-Myanmar relations and also India's need to counter China's growing influence in its neighborhood. The paper also argues that as a neighbor friend and partner of Bangladesh, the role of India in Rohingya crisis has become a global expectation for peace and conflict resolution.

\section{Keywords}

Myanmar, Rohingya, India, Humanitarian, Geopolitical.

\section{INTRODUCTION}

The Rohingya, described by the UN as the world's most persecuted people, have faced heightened fears of attack since dozens were killed in communal violence in 2012. According to Amnesty International, more than 750,000 Rohingya refugees, mostly women and children, have fled Myanmar and crossed into Bangladesh after Myanmar forces launched a crackdown on the minority Muslim community in August 2017, pushing the number of persecuted people in Bangladesh above 1.2 million. Since August 25, 2017, nearly 24,000 Rohingya Muslims have been killed by Myanmar's state forces, according to a report by the Ontario International Development Agency (OIDA). More than 34,000 Rohingya were also thrown into fires, while over 114,000 others were beaten, said the OIDA report, titled "Forced Migration of Rohingya: The Untold Experience. "Some 18,000 Rohingya women and girls were raped 
by Myanmar's army and police and over 115,000 Rohingya homes were burned down and 113,000 others vandalized, it added. Other than Bangladesh, the Rohingyas, over decades of persecution and crackdowns, have also landed in countries like Malaysia, Thailand, Pakistan, the United Arab Emirates (UAE), Saudi Arabia, and India. In India, as reports suggest, most of them made it after the 2012 wave of violence in Rakhine.

The Rohingya people are a Muslim minority group residing in the western state of Rakhine, Myanmar, formerly known as Arakan. The religion of this ethnic group is a variation of the Sunni religion. The Rohingya people are considered "stateless entities", as the Myanmar government does not recognize them as an ethnic group. Thus, they lack legal protection from the Government of Myanmar, are regarded as refugees from Bangladesh, and face strong hostility in the country. The Rohingya people have been described as one of the most persecuted people on earth. The Rohingya often try to enter Southeast Asian states illegally and request humanitarian support from host countries. Now a days, the issue which is known as,' Rohingya Crisis' has become a tragedy that was making for over several decades and concerns the plight of hundreds of thousands of people belonging to the Rohingya Muslim minority community in Myanmar's Rakhine State. The United Nations (UN) has described the violence against the Rohingya community as a 'textbook example' of ethnic cleansing.

One important feature of the current refugee movements is that the people fleeing and seeking asylum are mostly Muslim. If the negative response of most western and European countries has many reasons ranging from high politics to regional security, a common thread that runs through is growing Islamophobia.

In November 2017, Myanmar and Bangladesh signed an agreement on repatriation of the refugee. The International community have urged Myanmar to speed up the process of repartition, though concerns remain on the long-term political issues including 'community reconciliation' and 'citizenship status'. Especially India has urged the world community to help Bangladesh deal with the huge Rohingya influx from Myanmar, saying it poses a threat to regional security. India recognizes the humanitarian burden on Bangladesh's society and economy, said the Security Outlook 2019 of the Association of Southeast Asian Nations (ASEAN) Regional Forum held on Friday, according to BSS, Bangladesh's state-run news agency.

This brief examines India's approach towards the Rohingya crisis and explores ways for India to strengthen its role. This report seeks to analyze the Indian state's policy response to the Rohingya crisis, through its political and humanitarian aspects; it examines the different steps taken by the government to project the Rohingyas as a 'threat to India's national security'; and it looks at the humanitarian aspect of the response offering an explanation about the underlying politics of humanitarianism. India's Rohingya position has two aspects. The first concerns the implications of India's stand on the Rohingya refugees and the second, how India can play a role in finding a solution to the crisis.

\section{CENTRAL RESEARCH QUESTION}

The way the Rohingya Muslims have been treated by the government under Prime Minister Narendra Modi of the Bharatiya Janata Party (BJP) is very different from the way other groups were treated by earlier dispensations. During and after the purge in Rakhine that started in August 2017, India has blocked their entry and called for the forceful repatriation of those Rohingyas already on its soil, a departure from the manner in which previous Indian governments dealt with refugees. This study seeks to understand what has led to such a change in policy — or at any rate, a change in practice - if it has taken place. While examining the government's different securitization moves, this report will attempt to answer the following questions:

$\checkmark$ What has motivated the Indian state to adopt a different policy towards Rohingya refugees?

$\checkmark$ How has the response to the Rohingyas been different, compared with that towards other refugee groups/inflows?

$\checkmark$ Does the influx/presence of Rohingyas overwhelm the local capacity? 
$\checkmark$ Do they encourage local conflict?

$\checkmark$ Do they pose a threat to the sovereignty and national security of India?

$\checkmark$ How India's Rohingya approach is viewed.

$\checkmark$ What is the importance of various factors about India's role on Rohingya crisis? These factors are: diplomatic, domestic political compulsions, humanitarian, security and geopolitical considerations.

$\checkmark$ What is the role of BCIM economic corridor and is China likely to dominate economically through this corridor?

$\checkmark$ Is India apprehensive about China's expansion lately about launching any project?

$\checkmark$ What is the Humanitarian and Geopolitical role in India's approach in Rohingya crisis?

The report will investigate the questions through the perspective of a humanitarian crisis and securitization.

\section{THEORETICAL FRAME WORK: ARGUMENT / COUNTER ARGUMENT}

Refugees who flee persecution, religious or ethnic, fall under the purview of international protection established in the form of various conventions like the Refugee Convention 1951, its 1967 protocol, other declarations and intergovernmental institutions like the UNHCR. Under these conventions, they are entitled to receive humanitarian assistance and legal help to secure refugee status. India is not a signatory to the UN refugee convention or its 1967 protocol. It has allowed the UNHCR to refugee convention or its 1967 protocol.

To analyze India's response to the Rohingya refugees, this report uses the policy yardstick for countries derived from different UN protocols and recommendations. Taking a clue from Lindvall4 (2015), the present study makes use of the main concepts of securitization theory to analyze the response of the Indian state vis-à-vis the Rohingya refugees in terms of: a) referent object - the entity which is claimed to be 'threatened', the Indian state in this case b) referent subject - the 'threatening' entity, the Rohingya refugees c) securitizing actor - the government or government representatives who represent the state. It also involves the media and other organizations.

Three phases are identified about India's role on Rohingya crisis where a combination of factors seemed to have shaped India's role in Rohingya crisis. In the first phase, Delhi took the side of the Myanmar government because it was concerned that raising the issue publicly might push Myanmar towards China as it was building relations with newly formed democratic government. India also has economic interests with its companies holding stakes in Shwe Gas field off the coast of Rakhine State. Along with energy interests and plans to build cross-border pipelines, India also has a connectivity interest to link its landlocked northeastern region with the Bay of Bengal through Rakhine State under a joint project with Myanmar that includes development of port at Sittwe, in land waterway in the Kaladan River, a road construction to connect it with India's Northeast. Delhi was wary that instability in the Rakhine State would have adverse effects on these interests. With growing security cooperation between the two countries, particularly in tackling cross-border ethnic insurgency in their shared border regions, India was careful not to upset the Myanmar regime. India's offer of relief assistance was a token of support to the Myanmar government as much as it was about its humanitarian concerns in a neighboring country. Thus, geopolitics, security and economic interests' government adopted a contrary position to the central government by expressing its support for the Rohingya refugees. External Affairs Minister Sushma Swaraj visited Dhaka on 9 October 2017 and reassured the Bangladeshi government of Delhi's support.

In the second phase, apart from geopolitics, humanitarian concerns and non-interference in internal affairs, two other factors appeared to have driven the Indian approach: the growing security concerns and the need for diplomatic balancing between Bangladesh and Myanmar. In the latter part of the second phase, Delhi's assessment allowed it to formulate three points that became the basis to drive its Rohingya approach: the first is the assessment that restoring "normalcy" can happen "only with the 
return of the displaced persons to Rakhine state." This position implied that the return of Rohingyas to Myanmar from Bangladesh and elsewhere would also mean the return of Rohingyas from India". The second point relates to Delhi's assessment of the situation that socioeconomic development in Rakhine State is "the only long-term solution." Therefore, the need for supporting and mobilizing resources for development on its own as well as urging the international community to assist development efforts in Rakhine has been prioritized. The third point relates to Delhi's returning people. Under the MOU, India pledged US\$25 million for a five-year 27 development project in Rakhine State. At the invitation of the Myanmar government, India joined the UNSC delegation that visited Myanmar in early May 2018 along with three 28 other neighbors, China, Laos, and Thailand. During Minister Swaraj's visit to Myanmar on 10-11 May 2018, she stressed the importance of "safe, speedy and sustainable return of displaced persons to Rakhine State." This indicates a step forward from the previous position when it called fodisplaced persons to Rakhine State." This indicates a step forward from the previous position when it called for "restraint" in handling the situation in Rakhine.

The concept of an "economic corridor" refers to the linear connectivity along a physical transportation channel such as a road, rail line or waterway within a defined space or location, linking various nodes of production, distribution and consumption, and supported by programs, policies, institutions and agreements that facilitate cooperation between the economic clusters along the corridor route. A quick review and open discussion demonstrate that an economic corridor might be required to satisfy two rather conflicting ideas. According to the first idea, referred to as the Delhi- Mumbai Industrial Corridor (DMIC) project, an economic corridor may be visualized to connect major urbanities with a view of advancing business groups by establishing and developing hubs, by building ocean, air or road gateways and consequently creating trade which will turn sub-regional distribution into a worldwide supply chain. the region. On the contrary, an economic corridor might also be planned to advance the flow of trade and improve isolated regional borders, or to give the opportunity for access to external connectivity to land-locked areas and nations. The theory of connectivity can be a good explanation in terms of defining the BCIM roadway project.

There is a view that with the Western world embroiled in its own challenges, there is a lack of global leadership. Under the circumstances, perhaps Delhi has framed an approach towards the Rohingya crisis without the need to concern itself about the reactions of the Western powers, which otherwise tend to preach to other countries from their self-appointed high-moral ground But yet China tried to fill in the leadership gap.

There are some arguments about India's role in Rohingya issue. Most of the audiences agree that the lack of a national policy framework on refugees has complicated India's handling of the Rohingya crisis. The first argument is current Rohingya approach has some elements of continuity, as it is "consistent with [India's] traditional hesitation about automatically designating asylum seekers as refugees. According to this line of thinking, India has conventionally "created disincentives" for refugees to "stay on in India permanently", citing the case of refugees from Bangladesh (East Pakistan then) during the 1971 war. India helped Bangladesh but did not regard those fleeing the country as refugees and that "ensured their return" to Bangladesh after the war. However, there seems to be a big difference between the BJP-led government's Rohingya approach and older ways of managing refugees.

The second explanation views the current approach as a departure from the past and analyses it from the perspective of potential implications on India. This argument is that the framing of the Rohingya crisis through the security argument is short-sighted as it could create more security challenges for India, including "greater radicalization" of a repressed community that could have serious "spill over" effects on India. As an analyst has argued, the issue with India's Rohingya approach "is not that it is placing security over humanitarian but that it is doing so in a way that is imprudent and likely to be selfdefeating." Moreover, given its historical bent towards protecting refugees, India must rise to the occasion and demonstrate that it is not solely driven by narrow domestic political interests. While maintaining a constructive engagement with Myanmar, Delhi has been able to convey to the Myanmar 
authorities that the only solution to the Rohingya crisis is the safe return of the refugees to Myanmar. Towards this end, India has operationalized the MoU on Rakhine State Development Programmed signed in December 44 2017. As Delhi continues its support to Dhaka with relief assistance for refugee camps in Bangladesh, an immediate requirement is in dealing with the impact of the current monsoon rains. India has been working closely with both Myanmar and Bangladesh in the security sector. Sharing of information is a key element of security cooperation to prevent terror groups from trying to radicalize Rohingyas in refugee camps.

At the end of August 2018, BIMSTEC is scheduled to hold its summit in Nepal. Delhi may use this platform to strengthen the grouping's growing security cooperation with the member states and offer financial assistance to the BIMSTEC Secretariat to play a role in humanitarian assistance and socioeconomic development in Bangladesh and Myanmar. Even as India engages with both ASEAN and BIMSTEC on the Rohingya crisis, a combination of both bilateral and regional engagements and coordination may prove to be more effective in producing tangible outcomes.

\section{LITERATURE REVIEW}

The persecution of the Rohingya Muslims, often referred to as the 'world's most persecuted minority', is a glaring example of statelessness and state-sponsored forced displacement, resulting in a severe humanitarian crisis. This is not a recent development, rather it is a result of many historical trajectories (Ibrahim 2016). Trade links with the Arab world through the seas brought them in close contact with Islam in the centuries to come. Moshe Yagar in his book 'Muslims of Burma' notes that the Rohingyas are actually the descendants of the Arabs and Persians who set up their trade colonies in this part of the world (Farzana 2017).

The Muslim influence in the Arakan region was considerable, and it had close ties with the Muslim rulers of Bengal: however, people from different faiths had lived in harmony here (Blackburn 2000) till the Burmese ruler arrived, and subjected the local Arakanese people to ill treatment: this first wave of persecution8 (Harvey 1967) resulted in over 200, 000 Rohingyas fleeing to British Bengal, now Bangladesh, to Chittagong and adjacent areas (Karim 2000) Thousands more were killed in an onslaught that also saw Islamic symbols razed to the ground (Iqbal 2017). Hiram Cox, a British resident diplomat to Burma, was later entrusted with the re-settlement and providing assistance to the people fleeing from the persecution of the Burmese kingdom (Ramachandra 1981). The Rohingyas, being mostly Muslim, wanted to become a part of erstwhile East Pakistan (now Bangladesh); some even claim that though there was lobbying for this cause, it did not eventually materialize (Tinker 1957 cited in Farzana 2017).

The actual problems for the Rohingyas started in 1962 when the military (Tatmadaw) seized control of the country (Taylor 2009). In 1977, the military started Operation Nagamin (Dragon King) to 'identify and screen' foreigners. As the Rohingyas were not recognized as an indigenous ethnic group, 200, 000 of them fled to Bangladesh. A year later, most of the Rohingyas returned, due to an UN-brokered repatriation deal between the two countries, but some stayed back.

Another major crackdown in Rakhine started in 1991 in which 2,50,000 fled to neighboring countries, mainly Bangladesh, to escape forced labor, religious persecution, and other human rights violations by the army. One more United Nations High Commissioner for Refugees (UNHCR)-mandated repatriation agreement ensured repatriation of more than 2,00,000 refugees from 1992 to 2004. The latest wave of violence that started was apparently triggered by an attack on police posts in northern Rakhine in August 2017 by Rohingya insurgents affiliated to the Arakan Rohingya Salvation Army (ARSA). Civilians were killed, women raped and entire villages were burned. More than 6,56,000 people fled to Bangladesh and, by January 2018, Bangladesh had become home to almost a million refugees (Relief web 2018).

India has not signed the international convention of refugees because it is skeptical of the 'Eurocentric' nature of the international refugee regime, but it has hosted refugees from neighboring countries, including Sri Lanka, Tibet, Bangladesh, Bhutan, Myanmar, Afghanistan, Pakistan and a few hundred 
refugees from other parts of the world as well. Some estimates put the number of refugees in India at $3,30,00022$. However, the latest UNHCR fact sheet (2016) mentions a total of 2,09,234 people of concern in India. In the absence of any national law on refugees, India has mostly dealt with them according to its political convenience (Banerjee 2014).

India has urged the world community to help Bangladesh deal with the huge Rohingya influx from Myanmar, saying it poses a threat to regional security. India recognizes the humanitarian burden on Bangladesh's society and economy, said the Security Outlook 2019 of the Association of Southeast Asian Nations (ASEAN) Regional Forum held on Friday, according to BSS, Bangladesh's state-run news agency.

India praised Bangladesh's generosity towards displaced people in the repo The report said bordering northeastern India, Myanmar's stability and prosperity is crucial for regional security. India has provided aid to Myanmar to facilitate the return of Rohingya to Myanmar's Rakhine state, the place of their origin. The agency reported on Saturday and is deeply conscious of the humanitarian and security implications of the displacement of nearly one million people (Rohingya) in Bangladesh from contagious areas of Rakhine state in Myanmar," said the outlook report.

The following literature drawn on for this review is almost entirely comprised of newspaper, articles and very few research papers. Given the fact that the crisis is still unfolding, no academic literature was found on the current situation though the review did come across a few papers on the historic problem of Rohingya refugees. The review found no literature looking at the impact of the Rohingya crisis.

\section{LITERATURE GAP}

Indian approach towards the Rohingya crisis has been viewed as contradicting its traditional position on refugees. As the Rohingya crisis unfolds, there is still a lot that India can do to facilitate the finding of long-term solutions. These actions will be key in determining India's regional and global standing. Minister Swaraj's Myanmar visit suggests that Delhi is committed to remain an active partner in ending the crisis, but this is only the beginning of what India can and must do.

\section{RESEARCH METHOD}

The study uses a discourse analysis method. Parliamentary and assembly debates, the speeches, interviews, statements of government representatives, including the Prime Minister, Home Minister, External Affairs Minister and statements or circulars issued by relevant government functionaries on the Rohingya issue have been analyzed. the discourse on the issue, i.e., how it was framed in the media including reportage, research reports, policy briefs, and press releases by different rights groups was analyzed.

The study has done mostly based on Secondary Data such as: Annual Report 2017-2018, journals, magazines, Articles from publishers, Newspaper, Internet.

\section{RESEARCH FINDING AND DISCUSSION}

\subsection{Humanitarian Role: Aid, Financing and Building House:}

$\checkmark$ 'Operation Insaniyat' was done by India in Bangladesh to provide relief assistance for refugee in Bangladesh.

$\checkmark$ Allowed to enter into the country without creating any issue or political resistance.

$\checkmark$ Maintain equal diplomacy with Bangladesh and Myanmar providing hostility to none.

$\checkmark$ Sushma Swaraj, then Minister of External Bangladesh in Humanitarian assistance proved the Indian tactical assistance to Bangladesh in humanitarian response.

$\checkmark$ The first portion of relief material consisting of 4.5 lakh food packs of rice, lentils, milk etc. was delivered in September 2017.

$\checkmark \quad$ In May 2018, the second portion of relief material consisting of 373 metric tons of dry, fish, milk powder, baby food, rain coats and gum boots to cater to the rainy season was handed over. 
Third phase or relief assistance of over 1 million liters of Super Kerosene Oil and 20,000 Kerosene stoves (September 17,2018).

$\checkmark$ On December 24, for the first time though, the Indian assistance will be distributed to not only the refugees but also among the local population whose lives have been severely impacted by the refugee influx. The assistance which will be given by the Indian high commission includes 2,25,000 blankets, 2,00,000 woolen sweaters and 500 solar street lights.

$\checkmark$ India recently built 250 homes for the refugees in Myanmar's Rakhine province for when they will return.

\subsection{Geopolitical Interest: Economic (Trade and Connectivity) and Political Interest:}

$\checkmark$ Myanmar is the gateway to India's 'Look East' Policy. India's isolated eastern and north eastern also stand to gain by higher trade and connectivity with China and the rest of Asia. India is going all out to strengthen its relationship with Myanmar to achieve its stated objective.

$\checkmark$ The Bangladesh-China-India-Myanmar (BCIM) economic corridor (EC) aims to connect Kolkata with Kunming, capital of the Yunnan province. It is a sub-regional organization of Asian nations aimed at greater integration of trade and investment between the four countries.

$\checkmark$ As part of the BRI, the BCIM-EC proposes to connect eastern China with South Asia that will also ultimately connect Southeast Asia through different modes for better economic and cultural connectivity. The initiative is designed to enhance connectivity in areas such as trade, infrastructure, investment, capital and people.

$\checkmark$ Road linkage between China and Nepal would greatly contribute to connectivity between China and South Asia. If Nepal and China are connected either by road or rail- understandably it is already in place - it then facilitates connectivity with India, Bhutan and Bangladesh. This connectivity then leads the countries to the warm water ports of Bangladesh. That should be a win-win for all the stakeholders, including the less developed Northeast India.

$\checkmark$ Both India and China have huge infrastructure projects in Rakhine such as India funded Kaladan multi-model project designed to provide a sea-river-land link to its remote northeast through Sittwe port and China funded Kyauk Phyu port, which is to be the starting point of an oil-gas pipeline and rail road link to Yunnan state of China. Though neither of these projects are in the troubled region of northern Rakhine, where Muslim Rohingya are a majority in a predominantly Buddhist country, the threat of terrorism spilling over to parts of Rakhine where they have invested and also into their own territories worries New Delhi and Beijing alike.

$\checkmark$ Myanmar is India's gateway to Southeast Asia. Myanmar is bridge east and an important ally for growing regional power.

$\checkmark$ A long geographical land border and maritime boundary in the Bay of Bengal with Myanmar.

$\checkmark$ India and Myanmar signed an MOU in July 2019 on bilateral defense cooperation.

$\checkmark$ Myanmar is strategically important to India as it is the only ASEAN country that shares border and India's security concern in upper western Myanmar adjacent to Naga self-administered zone.

\subsection{Economic Interest:}

$\checkmark \quad$ India and Myanmar signed a trade agreement in 1994.

$\checkmark$ Indian companies have invested in Myanmar's energy sector.

$\checkmark$ Nearly 40.000 Rohingya refugees are in India that is high economic costs.

$\checkmark$ India is a supplier of defense equipment to Myanmar. India delivered an initial batch of indigenously built torpedoes for the Myanmar Navy; total cost estimated at $\$ 37.9$ million and Myanmar's oil and Gas resources, vital to the energy-scarce and rapidly developing India. 


\subsection{Political Interest:}

Treaty of Friendship with Myanmar was signed in 1951 and as a result Indian President Ramnath Kovind visited Myanmar in December 2018.

\subsection{Summary of India's Refugee Policy Towards Rohingya Issue}

$\checkmark$ Competition with China.

$\checkmark$ India's economic interests and ambitions in Myanmar.

$\checkmark$ The fragile geopolitics of India's nor east.

$\checkmark$ The rising Hindu nationalism in the nation.

$\checkmark$ Cooperation in forums such as ASEAN and BIMSTEC strengthen the relationship between India and Myanmar.

\section{CONCLUSION}

The Rohingyas have suffered for decades while the international community has been a mute spectator. They have been killed, tortured, forced to flee; they have starved to death. The Indian state's insistence on treating the Rohingya issue as one of development is problematic as it ignores the basic fact that this is a problem of political exclusion. It has offered development aid in Myanmar in the form of the Rakhine Development Programme but has never taken up the issue of Rohingya citizenship with the Myanmar government. Although the Myanmar and Bangladesh governments agreed upon a repatriation agreement, there has been no action on the ground in this regard. The people are unwilling to return as the government of Myanmar has done little to address the issue of the deprivation of rights of the Rohingyas. In such a scenario, the Indian government's plans for a forced repatriation of Rohingyas speak of its disregard for humanitarian values. Instead of forced repatriation, the Indian government must use its good offices to bring the Myanmar government to first acknowledge the wrongs that have been done to this community and then mediate a solution that addresses the root problems of political exclusion and citizenship. This can pave the way for a voluntary and dignified repatriation, primarily from Bangladesh and India as well. There should also be a concerted effort on India's part to extend its 'Operation Insaniyat' inside Bangladesh for the development of affected areas such as Cox's Bazar, in addition to providing basic services that have been sent in a couple of tranches. So far, the Indian approach towards the Rohingya crisis has been viewed as contradicting its traditional position on refugees. As the Rohingya crisis unfolds, there is still a lot that India can do to facilitate the finding of long-term solutions. These actions will be key in determining India's regional and global standing.

\section{REFERENCE}

Bangladesh-China-India-Myanmar (BCIM) Economic Corridor: Challenges and Prospects: Mohd Aminul Karim and Faria Islam: The Korean Journal of Defense Analysis Vol. 30, No. 2, June 2018, 283 - 302

Krim. Md A. and Faria Islam. 'Bangladesh-China-India-Myamnar (BCIM) Economic Corrider: Challenges and prospects' (2018)

Rohingya refugee crisis: impact on Bangladeshi politics: Iffat Idris GSDRC, University of Birmingham 3 November 2017

Policy Report: No 24: Mudasir Amin: The Hindu Centre for Politics and Public Policy

Rohini J. Haar, Karen Wang, Homer Venters, Satu Salonen, Rupa Patel, Tamaryn Nelson, Ranit Mishori, Parveen K. Parmar. (2019) Documentation of human rights abuses among Rohingya refugees from Myanmar. Conflict and Health 13:1.

Yhome. Khriezo. 'Examining India's stance on the Rohingya crisis' Observer research Foundation (2018) 